\title{
TRANSITION OF HOSPITAL ACUTE-CENTRIC TO LONG TERM CARE IN AN AGEING POPULATION IN HONG KONG - IS IT AN ISSUE OF SERVICE GAP?
}

\author{
Tommy K. C. Ng, Ben Y.F Fong, Catherine K. Y Kwong \\ The Hong Kong Polytechnic University
}

Correspondence: kctng@speed-polyu.edu.hk

\begin{abstract}
Health expenditure at around $5.7 \%$ of GDP is low for a developed society like Hong Kong, where a dual track of public and private services in its health care system is unique. The low level of expenditure has been steady over the last three decades, apparently not affected at all by a major change in the Government in 1997. The public and private sections have equal share of the total health dollars consistently over the years, despite the increase of Government's annual spending from $11 \%$ to $17 \%$ since 1990 , implying a similar trend in the private sector, which is funded predominantly by out of the pocket expenses with some insurance contribution. However, Hong Kong has the longest life expectancy in the world. This has resulted in the increase in the demand for health and long-term care, casting doubt on whether the traditional model of financing and delivery of care will be sustainable. The Government has pledged that that no one is denied adequate medical treatment due to lack of means, a stance in existence for decades and being reflected by the steady state of public and private share of health expenditure. Apart from two major re-structuring of the governance system, there has been little change in the service provision organisations. The system is often criticized for being heavily hospital based and acute-centric, particularly in the public services. Primary care is taken up predominantly by the private sector, mostly in clinical services, not focusing on prevention. It is apparent that there is a significant service gap, that needs to be examined and addressed systematically before a practical solution can be formulated. A more holistic, humanistic and better integrated system of care, with innovative care patterns, shall be the way forward.
\end{abstract}

\section{KEYWORDS}

ageing, long-term care, community elderly health, service gap

\section{A DUAL-TRACK SYSTEM OF HEALTH CARE}

The health care system of Hong Kong runs on a dual-track basis encompassing the public and the private sectors that operate independently. Public health services have been playing a very important role in acting as the safety net for the entire community as health systems with higher public expenditure on health care provide better financial protection for individuals. [1] The private health care sector provides the alternative choices and more easily accessible services to individuals who are willing and can financially afford, either out of pocket or through insurance, to pay for the expensive cost-recovery private health services. The health care system of Hong Kong is thus unique in having a mixed welfare and free market subsystems operating in parallel but "independently" in the public and private sectors respectively. [2]

\section{ACHIEVEMENTS AND THREATS}

Health expenditure in Hong Kong has been fairly steady over the last three decades at around 5.7\% GDP and this is low for such an economically developed society. Both the public and private sections have equal share of the total health dollars consistently over the years, despite the increase of Government's annual spending from $11 \%$ to $17 \%$ since 1990, or in terms of money, from 10 to 60 billion 
Hong Kong dollars (HK\$), implying an equally similar trend in the private sector, which is funded predominantly by out of the pocket expenses with some insurance contribution, mostly through employee benefits.

However, Hong Kong has achieved unexpected health statistics in having low infant and maternity mortality rates, and a rather surprising result of achieving the longest life expectancy in the world among its residents in this tiny and crowded city, that is full of stressful urban life and "unhealthy" daily activities. Life expectancies for male and female Hong Kong citizens were 81.9 years and 87.6 years respectively in 2017 while the corresponding projected figures would be raised to 87.0 and 92.5 in 2064. [3] Its population of 7.5 million will age rapidly, more than most industrialized countries and much faster than previously expected. [4] The proportion of over the age of 65 is projected to rise markedly from 15\% in 2014 to 33\% in 2064. [3] People aged 80 years or above will surge from the current $4.6 \%$ to $15.9 \%$ in 2064 . [5]

The ageing population will have important repercussions on the financing and delivery systems of health and longterm care (LTC), because about one third of them have one or more life-style related non-communicable conditions requiring LTC services. Furthermore, escalating medical costs are expected because of the advances in technology, particularly in the diagnostic methods and resource-intensive treatment of diseases such as cancers.

The situation is complicated by a very low birth rate, being one of the lowest in the world and will make the predominantly tax-based public funding for health and community services unsustainable in future. [6] The health system is very hospital based and acute-centric. The public hospital system provides over $90 \%$ of all inpatient services at a very high subsidisation rate and hence nominal charges to the users, stretching the public hospitals to the limits with long waiting lists of patients and unrealistic waiting period for emergency and specialist services. [2]

\section{THE CHALLENGES}

The Hong Kong Government has been able to meet the increase in health expenditure, including a number of development and re-development projects of public hospitals in recent years. The private sector has been growing to meet the local demand as well as the increasing number of users from across the border. There are more medical groups and a new private hospital was opened in 2017 . Some of them are listed companies.

The rising health expenditure appears to grow at a rate faster than that of the economy. [1] The important question of sustainability of the local health care system in the long run has been on the public agenda. Thus, effective measures in the financing and service delivery of health services in the community and LTC are paramount to ensure accessibility and quality of services by the people at large.

The existing health service model is highly "acute carecentric" and hospital-based because of the lack of a welldeveloped primary care system in Hong Kong. The traditional model of financing and delivery of care has created huge problems in terms of sustainability, patient's best interests, and equity, while a stronger primary health care will lead to better health of the population at lower cost and resulting in greater user satisfaction. [7]

The current funding pattern creates incentives for the general public, especially the elderly, to over-rely on public hospitals for care, as the services provided by public hospitals are heavily subsidized, while those provided by private practitioners in the community are not. The Government has pledged that policies are carried out effectively to protect and promote public health, provide lifelong holistic health care to every citizen of Hong Kong, and ensure that no one is denied adequate medical treatment due to lack of means, a stance in existence for decades and being reflected by the steady state of public and private share of health expenditure in the health system. [8]

The Government has promoted public-private partnership to relieve the burden from the public to private sector. The Elderly Health Care Voucher Scheme was launched in 2009 to offer to elderly aged above 65 an annual voucher amount of HK\$2,000 for making good use of primary care, including curative and preventive service. [9] However, it is found that many elders would not consider going to the private services because of concern about the affordability after having used the voucher. Those elderly with higher level of education would be more willing to pay. [10] Hence, the Government needs to find a solution to reduce the high demand in the public sector. [11] 
Health care systems in every country or region undergo changes on the delivery and management of health care services according to meet the needs of modern society. The factors include increasing ageing populations, limited resources, technological advancements and higher patient anticipations. [12] Apart from two major restructuring of the governance systems, i.e. management of all public, heavily funded hospital services under the statutory Hospital Authority in 1991 and reshuffling of policy secretariats in 2000, there has been little, if any at all, change in the service provision organisations. General outpatient services of the Hospital Authority and public campaigns and targeted preventive services by the Department of Health are available to the public, whereas primary care is predominantly, $80 \%$, provided by the private sector, mostly in clinical services, not focusing on prevention or education.

\section{IMPACTS OF AGEING POPULATION}

Among all persons aged 60 or above, $48.8 \%$ had one or more chronic and degenerative conditions in 2000, including stroke and cancers, and the percentage has risen $61.8 \%$ in 2013. Likewise, about a third suffer from one or more disabilities such as restriction in body movement and seeing difficulty. These phenomena have resulted in rising demand for LTC services for the elderly, that are equally important to the clinical health services. Most elderly people prefer to remain living in their own home. [5] Community elderly care and support services allow the older population to live in the community they are familiar with, or in the age-friendly environment that is conducive to active ageing where they can stay healthy, active and independent as advocated by the Government, for as long as possible. [13]

There are increasing demand for residential care services and community care services by the frail elderly, and the need for a comprehensive active ageing policy catering to the well or able-bodied elderly. [5] There are also services supporting the family and carers. With increasing diversity of community elderly care and support services, an integrated approach is adopted by the Social Welfare Department to facilitate access to the three types of community support services for the elders, including elderly centre services, community care services and other support services. [14]
There were 26,325 subsidized residential care places in 2014 to 2015, while the number of elderly applicants on the Central Waiting List was 31,349. The average waiting time was 37 months for admission to these homes. 5,568 applicants on the waiting list passed away before being offered a place, an all-time high in the last decade. The average waiting time for purchased residential home places provided by the private sector was shorter at just eight months. [5]

\section{COMMUNITY ELDERLY CARE}

Primary care service is widely recognized as the central to health and social services acting as a first point of contact and a 'gateway' to the following secondary, tertiary and specialized health care services, with aims at detecting health risks early and thus improving general health conditions as well as preventing hospitalization and unnecessary institutional residential care. However, spending in primary care by the public often accounts for less than $40 \%$ of the total health dollars. [1] This is very much the case in Hong Kong. Community health service is one of the components of primary care providing community nursing services, geriatric assessment, psychiatric nursing services, and other allied health services by family doctors or general practitioners, community-allied health practitioners and also trained home caregivers, available in day care centres or at the elderly's homes. $[5,15]$ It helps reducing the reliability on acute hospital services and thus the demands on inpatient services, while at the same time maximizing the efficiency and effectiveness on primary care services and facilitating patients' rehabilitation. [16]

The Government's Department of Health has established the Elderly Health Service of Elderly Health Centres and Visiting Health Teams in all eighteen administrative districts since 1988 for people over 65 years of age at very low charge, but with a membership system. Over the years, 45,094 members have benefited by the scheme as in 2017 . an equivalent to only $4 \%$ of the entire elderly population. Officially 21,800 elderly people are on the waiting list with a waiting time for first enrolment at 6.8 months. This is unrealistic, and the service gap is huge as there are 1.25 million elderly people in our population. $96 \%$ of them are not in the service network. [15]

Insufficient medical and social resources of the elderly are revealed from a study in Hong Kong. [17] The lack of regular 
source of care might be one the reasons for the elderly perceived poor health. Furthermore, the inadequate accessibility and availability of primary care service has led to overreliance on the public hospital accident and emergency departments. Although the private sector can provide opportunities for the elderly to consult the doctors, the high costs of the private services and long waiting time in the public sector are the main barriers for the elderly to manage their chronic diseases.

Appropriate care patterns and the application of innovation and technology in home or community-based elderly care services are essential in a continuous and integrated health care system. At the community level, a more holistic, humanistic and better integrated system of care should be the way forward. This approach must be supported by political commitment and appropriate governance frameworks. [18] Services should be tailored to the needs of individuals and the Government policy should be steered to allocating the needy additional resources to community elderly care, in order to address inadequacies in the system. [19]

LTC planning is important in allowing the elderly and their family to tackle their health and social needs better. Similarly, understanding the utilization patterns is essential in shaping the policy for the development of LTC services. There are few studies on the plans and expected utilization of LTC services in Hong Kong, resulting in a research gap. [20]

\section{PATH TO IMPACT}

It is apparent that there is a significant service gap, that needs to be examined and addressed systematically before a practical solution can be formulated. A better understanding of the needs in community elderly health services will help to formulate the appropriate strategic plan to provide community elderly services in the appropriate and effective way, and to reduce the demand for the expensive hospital and residential care services. The gap in the service and practice of community elderly care should be analysed. The elderly has contributed so much to our society throughout their life and it is a return they legitimately deserve and logically expect. Until the society, particularly the Government, the community, the professionals and providers, takes an interest in community elderly care and ensures the care is provided to the needs, the entire society still owe our senior citizens a service in their last leg of life. We subscribe to the notion of "respect our elderly, love our elderly, and protect our elderly".

The path to impact includes the identification of opportunities for improvement in terms of service delivery, accessibility and quality and for formulation of practical solutions in policy, funding and innovative care patterns in services to the elderly population in our society, with the aim to promote a more holistic, humanistic and better integrated system of care, which has to be fully supported by political commitment and appropriate governance frameworks. Elderly in our community will benefit from the needy services, resulting not only in healthy ageing but also happy life. Ultimately Hong Kong becomes an age-respect society, with the most appropriate approach to elderly care.

\section{ACKNOWLEDGEMENTS}

The work described in this paper was partially supported by a grant from the Research Grants Council of the Hong Kong Special Administrative Region, China (Project No. UGC/IDS24/18).

\section{References}

1. World Health Organisation (WHO). Public spending on health: a closer look at global trends [Internet]. 2018 [cited 1 February 2019]. Available from: https://apps.who.int/iris/bitstream/handle/10665/2767 28/WHO-HIS-HGF-HF-WorkingPaper-18.3-eng.pdf

2. Ko WM. Speech by the Secretary for Food and Health, Dr Ko Wing-man, at the Asian Ministers panel discussion session of the World Health Summit Regional Meeting - Asia in Singapore [Internet]. 2013 [cited 1 February 2019]. Available from:

https://www.fhb.gov.hk/en/press_and_publications/sp eech/2013/sp130409.htm

3. Census and Statistics Department. Hong Kong Population Projections 2015-2064. Hong Kong: Hong Kong Special Administrative Region Government [Internet]. 2016 [cited 1 February 2019]. Available from: http://www.statistics.gov.hk/pub/B1 120015062015XXXX B0100.pdf 
4. Chung RY, Tin KYK, Cowling BJ, Chan KP, Chan WM, Lo SV, Cooper J Levington A, Abbott S, Meyer J. Partnerships for skills training in care-home sector. Primary Health Care Research \& Development. 2009; 10:284-289.

5. Legislative Council Secretariat. Challenges of population ageing. Research Brief, Issue No. 1, 2015 2016. 2015.

6. Secretariat of the Steering Committee on Population Policy. Thoughts for Hong Kong: Public Engagement Exercise on Population Policy. Chief Secretary for Administration's Office, Hong Kong; 2013.

7. Atun R. What are the advantages and disadvantages of restructuring a health care system to be more focused on primary care services? Copenhagen, WHO Regional Office for Europe, Health Evidence Network report [Internet]. 2004 [cited 1 February 2019]. Available from: http://www.euro.who.int/document/e82997.pdf

8. Lam AHY. Strategies of Hong Kong's Healthcare System in Ageing Population. Official Conference Proceedings of The Asian Conference on Ageing \& Gerontology. The University of Hong Kong, Hong Kong; 2017.

9. Health Care Voucher. Background of Elderly Health Care Voucher Scheme [Internet]. 2018 [cited 2019 Feb 25]. Available from:

https://www.hcv.gov.hk/eng/pub_background.htm

10. Liu S, Yam CH, Huang OH, Griffiths SM. Willingness to pay for private primary care services in Hong Kong: are elderly ready to move from the public sector? Health policy and planning. 2012; 28(7), 717-729.

11. Schoeb V. Healthcare Service in Hong Kong and its Challenges. The Role of Health Professionals within a Social Model of Health. China Perspectives. $2016(2016 / 4), 51-58$.

12. Thompson J. Transforming Health and Social Care in Northern Ireland - Services and Governance [Internet]. 2016 [cited 1 February 2019]. Available from: http://www.niassembly.gov.uk/globalassets/documen ts/raise/publications/2016-2021/2016/health/4016.pdf 13. Fong BYF, Law VT. Ageing in place. In Fong BYF, Ng A, Yuen $P$, editors. Sustainable Health and Long-Term Care Solutions for an Ageing Population. Hershey, PA: IGI Global; 2017. p. 259-276.
14. Social and Welfare Department. Community Support Services for the Elderly [Internet]. 2017 [cited 1 February 2019]. Available from:

https://www.swd.gov.hk/en/index/site_pubsvc/page_ elderly/sub_csselderly/id_introduction/

15. Legislative Council Secretariat. Elderly health services. Statistical Highlights ISSH21/17-18. 2018.

16. Tulchinsky T, Varavikova E. What is the "New Public Health"? Public health reviews. 2010; 32(1):1-25. doi: 10.1007/BF03391592

17. Wong SYS, Zou D, Chung RY, Sit RW, Zhang D, Chan D, Yeoh EK, Woo JW. Regular source of care for the elderly: a cross-national comparative study of Hong Kong with 11 developed countries. Journal of the American Medical Directors Association. 2017;18(9), 807.e1-807.e8.

18. Legislative Council Secretariat. Policy measures to promote smart elderly care services in selected places. Information Note IN07/17-18. 2018.

19. Cheng CPW. Elderly care as one of the important government policy agenda (Editorial). Hong Kong Med J. 2018; 24:442-3.

20. He AJ, Chou K. Long-term care service needs and planning for the future: a study of middle-aged and older adults in Hong Kong. Ageing and Society. 2019; 39 (2):221-253. doi.org/10.1017/S01 44686X17000824 